\title{
CRÓNICA DE UNA LEY NO NACIDA: LA REFORMA ELECTORAL PARA LA ELECCIÓN DIRECTA DE ALCALDES.
}

Inmaculada Gemma Burkhardt Pérez.

Profesora Contratada Doctora de Derecho Constitucional.

Universidad de Almería.

Email: burkh@ual.es

Durante el verano de 2014 ha ocupado la atención pública la propuesta surgida del Comité Ejecutivo del Partido Popular (PP) sobre la elección directa de los alcaldes, una medida que, de ser aprobada en sede parlamentaria, habría de incidir en los comicios locales a celebrar el próximo mes de mayo de 2015. Esta innovación se inscribe en un paquete más ambicioso de reformas legales orientadas a la regeneración democrática. El dato más importante a destacar en estos momentos es la falta de concreción tanto del conjunto de medidas propuestas como de la que ahora es objeto de atención singular, dado que no ha tomado cuerpo en una iniciativa parlamentaria del Gobierno de España ni del partido que lo sustenta en las Cortes Generales con mayoría absoluta; tan solo se ha presentado mociones en algunos Ayuntamientos y Diputaciones Provinciales en este sentido. No obstante, en el debate político se ha avanzado que la finalidad de la propuesta es lograr el gobierno municipal de la lista electoral más votada, a la que se aparejaría el mecanismo del bonus o premio de mayoría, de modo que la lista que obtuviera el cuarenta por ciento de los votos lograra la mayoría absoluta a efectos prácticos.

El contexto en el que nace una proposición de esta naturaleza es el del descontento generalizado de la población hacia las instituciones políticas, del que la evidencia más saliente es el auge de nuevos movimientos sociales que han puesto de manifiesto su 
potencial electoral en las elecciones al Parlamento Europeo de 25 de mayo de 2014. El resultado de dichas elecciones no es extrapolable al contexto nacional dada la configuración de la circunscripción electoral, pero indica con claridad el retroceso de los partidos tradicionalmente mayoritarios, que obtuvieron tan solo treinta de los cincuenta y cuatro escaños disputados - el PP obtuvo el 26,06 por ciento, y el Partido Socialista Obrero Español (PSOE) el 23 por ciento de los votos- y la irrupción de fuerzas políticas canalizadoras de las nuevas demandas sociales, susceptibles de alterar el patrón bipartidista de nuestros sistemas de gobierno, destacadamente PODEMOS, con el 7,97 por ciento de los votos y cinco escaños. Obtuvieron representación parlamentaria otros grupos de nuevo cuño como Coalición por Europa (3), La Izquierda por el Derecho a Decidir (2), Ciudadanos (2), Los Pueblos Deciden y Primavera Europea, ambos con un representante. La representación de las fuerzas políticas de izquierdas, pese a sus diferencias internas, resulta reforzada en unas elecciones de este tipo obteniendo mayoría de escaños, del mismo modo que se refuerza la presencia de partidos y grupos que son minoritarios en el contexto nacional. El resultado de estos comicios parece reproducirse en las últimas encuestas electorales, que indican un claro retroceso cuantitativo del partido popular y el riesgo de perder alcaldías de singular importancia, como Valencia o Madrid.

Sin duda, el conjunto de piezas que articulan el sistema electoral es uno de los pilares que ha sustentado el tipo de democracia por la que se optó en la época de la transición política y que tomó cuerpo en la Constitución de 1978, con algunos elementos dotados de particular rigidez. Es innegable el carácter polivalente del vocablo "democracia” y su adaptabilidad a las muy distintas formas de entender y de hacer la política. Por definición es democrático el ejercicio del poder por el "demos"; entiéndase por éste el conjunto de ciudadanos incluidos en el censo decimonónico, el conjunto de hombres libres de los sistemas clásicos griego y romano, o la totalidad de la población mayor de edad y no privada judicialmente del derecho de sufragio, que es la acepción vigente en las democracias occidentales. Y es democrática tanto la participación directa del demos en la formación de las decisiones públicas como la que se efectúa mediante representación. Otras decisiones que van a modelar el concepto de democracia resultante son la selección de las instituciones de democracia directa y representativa y la importancia respectiva de cada una de ellas, la definición de la circunscripción 
electoral, el sistema de conversión de votos en escaños, la existencia de cláusulas barrera, entre otras. Dado su carácter conformador del modelo de Estado las opciones electorales básicas han sido dotadas entre nosotros de naturaleza constitucional, en algunos casos con carácter formal -así las circunscripciones electorales, la fórmula electoral o el mandato parlamentario- y en otros con carácter material. De acuerdo con el artículo $81 \mathrm{CE}$ el régimen electoral forma parte del ámbito material de la legislación orgánica, lo que se traduce, desde luego, en la necesidad de una mayoría cualificada para la adopción de decisiones al respecto; pero, más allá de este elemento cuantitativo, la naturaleza de esta fuente del derecho apela a la conveniencia de un consenso amplio entre las fuerzas parlamentarias para la adopción de decisiones que afecten a este ámbito de la convivencia política.

La nueva correlación de fuerzas políticas parece haber acelerado la dinámica de cambio sobre la importancia relativa de cada uno de estos factores, en sentidos claramente opuestos. En la línea de propiciar la reforma del sistema electoral desde la propia Constitución se inscriben las proposiciones presentadas por el Grupo Parlamentario Mixto y la Izquierda Plural para reforzar la participación política y el pluralismo en el régimen electoral (iniciativa 100/000003), registradas en el Congreso de los Diputados en enero de 2012 y en mayo de 2013 y actualmente retiradas. Las proposiciones de reforma de la ley Orgánica de Régimen Electoral General, de 19 de junio de 1985 (LOREG), obedecen a las iniciativas del Grupo Parlamentario Unión Progreso y Democracia (UPyD) para garantizar una mayor proporcionalidad (10 de septiembre de 2014) y del Grupo Mixto para derogar el artículo 182.2, que permite elegir como concejales a ciudadanos que no participaron en el correspondiente proceso electoral (27 de junio de 2014).

El propósito del PP parece que tomaría cuerpo como una reforma de la LOREG, dado que a los fines a los que viene a servir no sería preciso alterar el texto de la Constitución, que permite en su artículo 140 que el Alcalde sea elegido, bien por los Concejales -sistema que articula la LOREG en su Título III- bien por los vecinos de forma directa. Ahora bien; debemos preguntarnos si es ése realmente el objetivo de la eventual reforma, dado que la tendencia presidencialista ya figura entre los rasgos caracterizadores de la autonomía local, con un papel muy reforzado de la figura del 
Alcalde, en sus atribuciones, en la exigencia de la responsabilidad política y también en el modo en que se articula la relación entre el elector y la lista electoral seleccionada, de carácter cerrado y bloqueado, apreciándose un fuerte componente personalista en la orientación del sufragio activo. La elección directa de un alcalde, en teoría, debería pasar por un desdoblamiento del proceso electoral para que el censo seleccionara, de un lado, a sus ediles y de otro al jefe del gobierno municipal. Pero no se ha planteado el debate en estos términos, pese a la posibilidad abierta por la Constitución. El objetivo parece ser, más bien, cristalizar en la LOREG el gobierno efectivo de la lista electoral que obtenga mayor representación en las urnas, sin que se haya concretado en sus términos precisos. Una medida de este tipo puede configurarse en modos muy diversos $\mathrm{y}$, de hecho, ha sido planteada por distintos grupos políticos en el curso de nuestra democracia, incluidos el PSOE, UPyD y Convergencia i Unió en la pasada Legislatura. En el presente caso parece presentar perfiles favorables a la fórmula de representación mayoritaria en detrimento de la tradicional fórmula proporcional, de modo que ope legis quedaran impedidas las coaliciones de gobierno municipal entre formaciones políticas que no hubieran obtenido el voto mayoritario de la población. Se ha hablado de incorporar a este esquema un elemento ajeno a nuestro sistema electoral, pero presente en otros -como el italiano, griego y francés-, del bonus o premio de mayoría, reforzando de este modo la posición del grupo municipal dominante, de modo que obtendría la alcaldía y la mayoría absoluta en el Pleno la lista que obtuviera el cuarenta por ciento de los votos. Se ha mencionado en el debate político la posibilidad de articular este gobierno mayoritario mediante un sistema de elección a doble vuelta, en caso de no obtener mayoría absoluta en la primera ronda electoral.

La indefinición de la propuesta popular y la proximidad de los comicios municipales, unida a la posibilidad técnica de que el partido en el Gobierno pudiera modificar en solitario la LOREG y la Ley de Bases del Régimen Local con sus solos apoyos parlamentarios han motivado una interpelación urgente en el Congreso de los Diputados debatida los días 16 y 17 de este mes de septiembre a iniciativa del Grupo Parlamentario UPyD, del que ha resultado una moción que ha traducido la negativa de todos los grupos parlamentarios a plantear en este momento de la Legislatura una reforma de esta naturaleza, a excepción, por supuesto, del Grupo Popular. Las argumentaciones más consistentes del debate han confrontado la idea lanzada por el PP con las 
recomendaciones de la Comisión de Venecia, órgano asesor del Consejo de Europa en cuestiones constitucionales ${ }^{1}$. Su Código de Buenas Prácticas en Materia Electoral, de 2003, considera adecuado a la legitimidad democrática de las reformas electorales, por su grado de afectación a un elemento sensible de la conformación del Estado, que éstas se realicen con el consenso necesario entre las fuerzas políticas y con un margen temporal suficiente respecto de los procesos electorales sobre los que hayan de proyectarse, de al menos un año. En el debate parlamentario se ha insistido en la improcedencia de cambiar las reglas de juego una vez iniciado el partido. La búsqueda de consenso sobre esta cuestión se ha postergado hasta este mes de septiembre y se ha limitado de momento a algunas conversaciones con el PSOE, si bien el portavoz parlamentario del PP ha hablado de la ampliación de los sujetos del debate a una mesa de partidos. La discusión en la Cámara ha evidenciado así mismo la crítica de la oposición parlamentaria a esta iniciativa por su carácter electoralista, tendente a favorecer al partido en el gobierno mediante una alteración del sistema que sólo persigue asegurar el poder político de un partido mayoritario.

En la hora de cierre de esta crónica no ha sido registrada en el Congreso la iniciativa parlamentaria que pudiera dar sustento a esta reforma del sistema electoral municipal. Entendemos, no obstante, que a pesar de que técnicamente podrían ser adoptadas las reformas legales que la hicieran posible, pesaría sobre ellas la sombra de la inconstitucionalidad por lesión del principio de representación proporcional y, muy posiblemente, del valor superior del pluralismo político, inserto en el mismo artículo 1 de nuestra Constitución. Lo que la Constitución indudablemente manda es que las normas que articulan la convivencia ciudadana sean establecidas de forma consensuada, adoptadas con la reflexión necesaria y que conformen un marco de seguridad jurídica y de respeto a los valores democráticos de libertad, igualdad y pluralismo.

\footnotetext{
${ }^{1}$ La denominación correcta de este grupo de trabajo es la de Comisión Europea para la Democracia a través del Derecho. El documento sobre buenas prácticas en materia electoral puede consultarse en el siguiente enlace: $\quad$ http://www.venice.coe.int/webforms/documents/default.aspx?pdffile=CDL$\underline{\mathrm{AD}(2002) 023 \mathrm{rev}-\mathrm{spa}}$
} 